\title{
Invertebrate Community Similarity in the Nglambor Intertidal Zone, Indonesia
}

\author{
Yoga Putra Aliyani ${ }^{1 *}$, Yunita Fera Rahmawati ${ }^{1,}$ Millade Annisa Muflihaini ${ }^{1}$ \\ ${ }^{1}$ Biology, Faculty of Math and Science, Universitas Negeri Yogyakarta, Colombo 1 Street, \\ Yogyakarta, Indonesia
}

\begin{abstract}
This study aims to investigate the community composition similarity of invertebrates in the Nglambor intertidal zone. The similarity of invertebrate communities in the Nglambor intertidal zone in Indonesia was studied in August and September 2020.. The data of occurring invertebrates and algae were obtained by plot method. Abiotic factors such as water $\mathrm{pH}$, light intensity, and salinity were measured at each station. The similarity in invertebrate communities among habitat types was determined using the Dice's coefficient, meanwhile to estimate similarities in habitat utilization we use Jaccard's coefficient in PAST 4 software. Both invertebrate community similarity and habitat utilization were displayed in an cluster dendrogram. A total of five phyla was recorded, comprising Annelida, Arthropoda, Echinodermata, Mollusca and Nemertea. Algae cover varies from each station with the average cover reaches $52 \%$. The result of the cluster analysis showed different models of invertebrate community similarity and habitat use that may be used for species conservation.

Keywords: Biodiversity, Intertidal Zone, Invertebrate, Nglambor, Similarity
\end{abstract}

\section{Introduction}

Nglambor Beach is located in Gunung Kidul, Indonesia. This beach has a coral rocky topography. Currently, Nglambor has experienced exploitation as a tourist object, snorkelling area, and marine life hunting. As a rocky beach, Nglambor has various invertebrate species. Especially on the occurrence of invertebrates there is a lack of information at this location. On a rocky beach, there are a lot of invertebrates, such as Echinoderms [1] and Mollusca [2] that important to ecosystem

The intertidal zone at Nglambor Beach has various types of substrates, such as sand, rocks, and coral fragments. The intertidal zone is the most temporally and spatially variable of all marine habitats. It ranges from sand and mudflats to rocky reefs and allows the development of a wide variety of plant and animal communities. The members of these communities are subject to the many and frequent changes imposed by waves and the ebb and flow of the tide [3].

Many living organisms inhabit intertidal areas, such as macroinvertebrates and macroalgaes [4]. In the intertidal zone, there is a reciprocal relationship between taxon, such

*Coressponding author : yoga.putra@yandex.com 
as algae which can affect the existence of macroinvertebrate [5]. Each species has specific and unique habitat specifications. Limited distribution and environmental specification conditions are the two main factors affecting the existence of a species in a community. Distribution limitation occurs when a species is unable to reach a location [6].

This study aims to investigate the similarity of the invertebrate community in the Nglambor intertidal zone. We expect that the result of this study can enrich the data of invertebrate species and habitat in Yogyakarta, Indonesia. This study is important to mapping the diversity of invertebrate and their habitat requirements.

\section{Materials and Methods}

\subsection{Study site}

This research was conducted from August to September 2020 at Nglambor beach. The research was located at $8^{\circ} 10^{\prime} 55$ "S and $110^{\circ} 40^{\prime} 44^{\prime \prime}$ E. Nglambor beach located in Tepus, Gunung Kidul Regency, Indonesia.

This study uses several tools such as $\mathrm{pH}$ meter to determine the $\mathrm{pH}$ of seawater, thermometer to measure water temperature, lux meter to measure the intensity of sunlight, salinity meter to measure salt levels and plot with a size of $1 \times 1$ meter.

\subsection{Methods}

The transect used in this study was a comb transect with four research stations. Comb transects are suitable for use in the intertidal zone, especially in Nglambor Beach. Each area of the research site was made of a transect with a length of 100 meters. Each transect was divided into 10 plots with a $1 \times 1$ meter plot and the distance between plots is 5 meters. Invertebrate observations were carried out visually, including invertebrates in the substrate as well as those attached to rocks. In each plot, the morphological characteristics, types, and the number of species were recorded. To determine the area of algae cover, a 1x1 plot method was used.

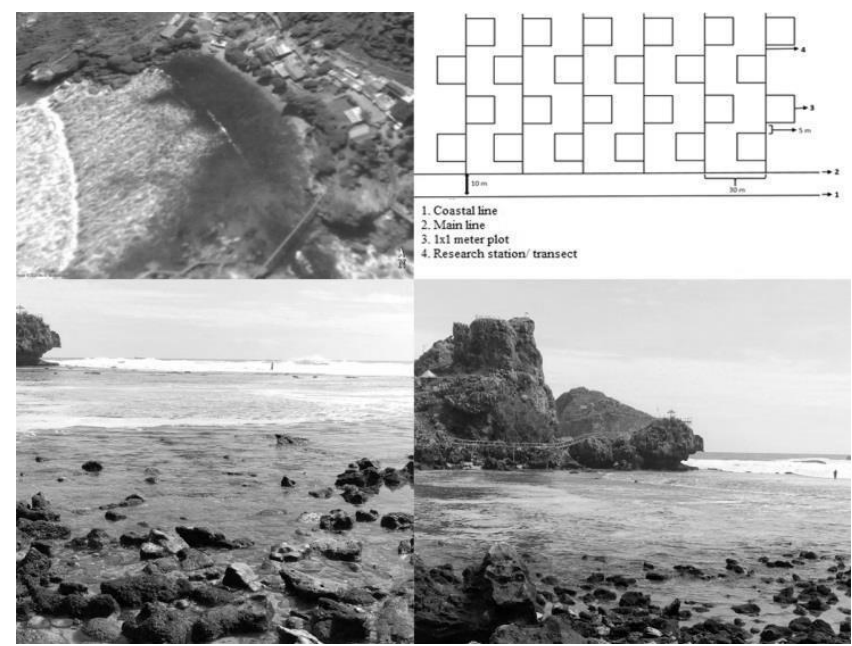

Fig 1. Research location in Nglambor Beach, Gunung Kidul, Indonesia. 


\subsection{Data analyses}

In this study, invertebrate similarity in the Nglambor intertidal zone was calculated using Jaccard and Dice indices. Similarity results were visualized in dendrogram with PAST 4 software [7]. To determine the similarity of the invertebrate community among the research station, theDice coefficient was used, while the Jaccard Coefficient was used in the habitat similarities. The Dice similarity puts more weight on joint occurences than on mismatches. The high sensitivity to heterogeneous data is an advantage that this coefficient has [8]. Jaccard Index formula is:

$\mathrm{a}=$ number of species common to two habitats

$$
\text { Jaccard index }=\frac{a}{a+b+c}
$$

$\mathrm{b}=$ number of species present in habitat $\mathrm{B}$ but absent in habitat $\mathrm{A}$

$\mathrm{c}=$ number of species present in site $\mathrm{A}$ but absent in site $\mathrm{B}$

Dice Index formula is:

$\mathrm{a}=$ number of species common to two habitats

$$
\text { Dice }=\frac{2 a}{2 a+b+c}
$$

$\mathrm{b}=$ number of species present in habitat $\mathrm{B}$ but absent in habitat $\mathrm{A}$

$\mathrm{c}=$ number of species present in site A but absent in site B [9].

\section{Results and Discussions}

\subsection{Invertebrate and Abiotic Parameters Nglambor Beach}

In this study, five different invertebrate phyla were revealed (Annelida, Arthropoda, Echinodermata, Mollusca, Nemertea) with a total of 423 individuals. The list of invertebrates on the nglambor beach can be seen in the Table 1 .

The phylum of Mollusca was the most common phylum found with 341 individuals (74.23\%) and 13 species. A very high population of molluscs shows that Nglambor Beach can support food, shelter, and other needs [2]. Generally, mollusks have a high population in tropical environments with rocky substrates [10]. Mollusca are animals that have high ecological adaptation potential and can be found in nearly every habitat. High mollusca population and low population of other phyla indicate that this location is receiving ecological pressure, so only phyla that are easily adaptable have a large number of individuals.[11].

The second most common phylum found were the echinoderms. This phylum uses the area between the rocks as a shelter. Echinoderms re invertebrates that generally live at the bottom of the water. In the marine food web, echinoderms acts as prey for some fish, crabs, and other marine animals [12]. Some members of echinoderms are important as it role in the coral reef ecosystem. The existence of several species of echinoderm can maintain the balance between algae and coral reef populations. Because it is herbivorous, it will eat algae that grow on coral reefs and reduce coral reef mortality [13]. 
Table 1. Invertebrates in Nglambor Beach

\begin{tabular}{|c|c|c|c|c|c|c|}
\hline Phylum & Family & Genus & St1 & St2 & St3 & St4 \\
\hline \multirow{8}{*}{ Annelida } & \multirow{2}{*}{ Neredidae } & Perinereis & 0 & 0 & 0 & 1 \\
\hline & & Nereis & 0 & 0 & 2 & 0 \\
\hline & \multirow[t]{3}{*}{ Sabellidae } & Branchiomma & 0 & 0 & 0 & 2 \\
\hline & & Sabellastarte & 0 & 5 & 4 & 0 \\
\hline & & Sabella & 0 & 1 & 1 & 0 \\
\hline & Cirratulidae & Chaetozone & 0 & 0 & 0 & 2 \\
\hline & \multirow[t]{2}{*}{ Amphinomidae } & Hermodice & 0 & 0 & 1 & 0 \\
\hline & & Eurythoe & 0 & 0 & 8 & 1 \\
\hline \multirow[t]{2}{*}{ Arthropoda } & Sesarmidae & Episesarma & 1 & 22 & 2 & 0 \\
\hline & Epialtidae & Tiarinia & 1 & 1 & 0 & 0 \\
\hline \multirow[t]{5}{*}{ Echinodermata } & Echinometridae & Echinometra & 1 & 0 & 0 & 19 \\
\hline & Holothuroidae & Holothuria & 1 & 0 & 1 & 0 \\
\hline & Ophiocomidae & Ophiochoma & 10 & 0 & 6 & 0 \\
\hline & Ophiomyxidae & Ophiarachna & 0 & 0 & 1 & 0 \\
\hline & Stomopneustidae & Stomopneustes & 0 & 3 & 0 & 4 \\
\hline \multirow[t]{13}{*}{ Mollusca } & Neritidae & Nerita & 26 & 13 & 0 & 0 \\
\hline & Aplysiidae & Aplysia & 1 & 0 & 0 & 0 \\
\hline & Mytilidae & Modiolus & 0 & 2 & 0 & 0 \\
\hline & Isognomonidae & Isognomon & 0 & 14 & 0 & 0 \\
\hline & Conidae & Conus & 36 & 0 & 0 & 1 \\
\hline & \multirow[t]{2}{*}{ Cypraeidae } & Cypraea & 2 & 18 & 0 & 0 \\
\hline & & Monetaria & 0 & 0 & 0 & 1 \\
\hline & Mitridae & Mitra & 0 & 0 & 0 & 9 \\
\hline & Muricidae & Thais & 10 & 0 & 2 & 0 \\
\hline & Pectinidae & Pecten & 2 & 0 & 0 & 0 \\
\hline & Arcidae & Barbatia & 12 & 0 & 12 & 0 \\
\hline & Trochidae & Trochus & 27 & 0 & 0 & 0 \\
\hline & Turbinidae & Turbo & 36 & 0 & 0 & 0 \\
\hline Nemertea & Valenciniidae & Baseodiscus & 0 & 0 & 0 & 9 \\
\hline
\end{tabular}

Table 2. Abiotic Parameters in Nglambor Beach, Gunung Kidul, Indonesia

\begin{tabular}{llll}
\hline \multirow{2}{*}{ Station } & \multicolumn{3}{c}{ Abiotic Parameters } \\
\cline { 2 - 4 } & Water $\mathrm{pH}$ & $\begin{array}{l}\text { Water } \\
\text { Temperature }\end{array}$ & Salinity \\
\hline 1 & 8,25 & 25 & 3.4 \\
2 & 7,1 & 28 & 3.6 \\
3 & 7,7 & 30 & 3.0 \\
4 & 6,7 & 29 & 4.0 \\
\hline
\end{tabular}

Based on abiotic parameters (Table 2), station 1 which is on the west side has the highest $\mathrm{pH}$. Station 1 is a cliff composed of calcium carbonate. Rocks that contain calcium carbonate $\left(\mathrm{CaCO}_{3}\right)$ can increase the $\mathrm{pH}$ of the water in the area by more than 7 . Stations 2 and 3 tend 
to have a $\mathrm{pH}$ near 7 as these locations are away from coral cliffs that contain a lot of calcium carbonate. Differences in $\mathrm{pH}$ will lead to differences in species populations as a result of environmental isolation.

Station 4 is a place which obtains the direct flow of sea water. Seawater flow was observed from west to east and periodically reverses direction. The water flow that occurs causes the water in the area to come directly from the ocean currents. Temperature variations at each research station were closely related to sunlight. At station 1 some cliffs can interfere with sunlight reaching the water maximally compared to other research stations so that the temperature is lower.

The salt content in the waters is related to the rate of evaporation and the supply of freshwater from the land. This research was conducted in the dry season that the evaporation occurs tends to be higher and will increase sea salt levels. The salt content of seawater can also be affected by underground river flows from the Gunung Sewu Geopark [14].

\subsection{Invertebrate similarity}

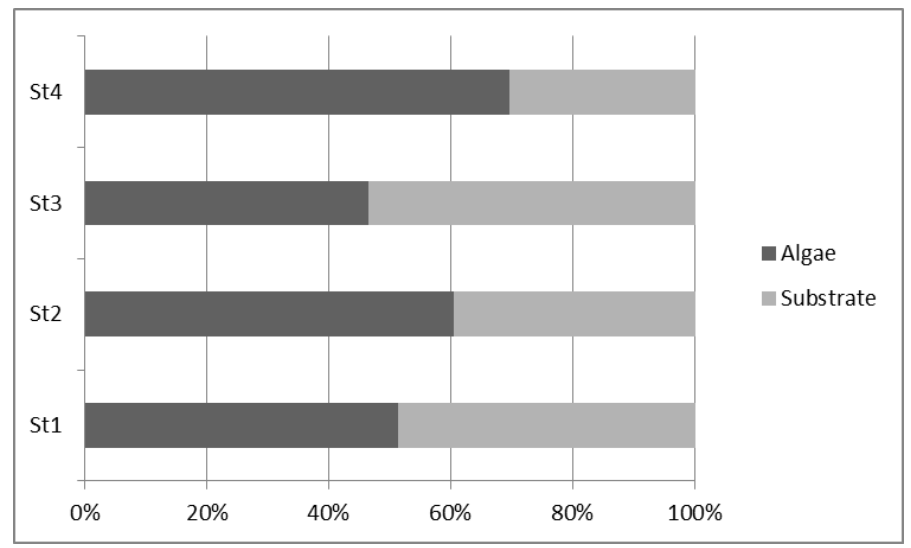

Fig 2. Algae and substrate cover at each research station

The highest value for algae cover was shown at station 4 which is an open area. The large area covered by algae is due to the large size of the rocks that provide a good attachment for the algae. Sunlight which more easily reaches the bottom of the water at station 4 gives an advantage to many algae because it is used for photosynthesis.

The algae that dominate at each station was Jania adherens which are firmly attached to rocks. The Jania adherens morphology and and the increase in its relative mass makes it possible to survive the waves [15]. The second dominant species was Enteromorpha flexuosa at stations 1 and 3. The long hair-like morphology of Enteromorpha flexuosa allows this species to survive on the beach which has big waves like in southern Java and it is easy to spread. Algal diversity and population may affect invertebrates because they provide shelter and food for certain invertebrates. The similarities of invertebrate community among research station can be seen in the figure 3 . and table 3 .

The similarity of the invertebrate community was divided into four clusters. Station 4 forms its own cluster, showing that the invertebrate community was very different than other stations.. It can be seen that the phylum Nemertea as only found at station 4 which indicates that there are supportive abiotic conditions.

Clusters branching starts at a similarity scale of 0.3 which separates stations 4 and 2 . The similarities at stations 4 and 2 are caused by similar algae cover areas, namely 69 and $60 \%$. Algae are needed by various types of invertebrates in the intertidal zone as a source of 
nutrition, camouflage, and shelter. The presence and abundance of algae affect the presence and population of invertebrates [16].

Species and extent of algal cover will affect differences in habitat characteristics, resulting in different types of invertebrates found. Gastropods are a species that is noticeably influenced by the extent of algal cover. Seasons also affect the presence and distribution of invertebrates [17]. Algae morphology can affect the type of invertebrates. Certain algae forms will support certain species [18].

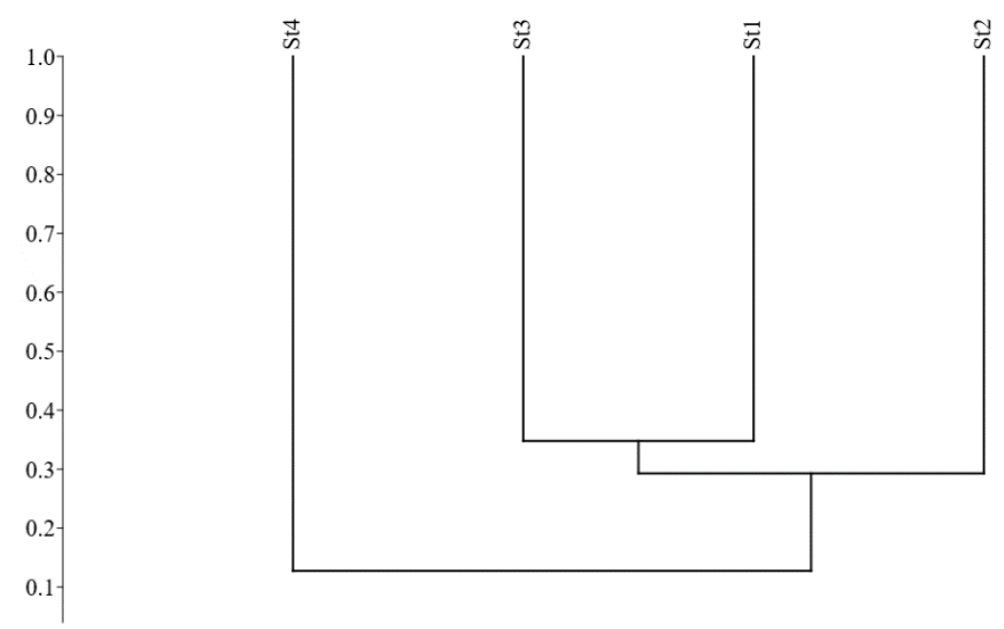

Fig 3. Dendrogram of the similarities of invertebrate community among research station based on Dice coefficient

Table 3. Dice similarity and distance index of invertebrate community among research stations

\begin{tabular}{lllll}
\hline & St1 & St2 & St3 & St4 \\
\hline St1 & 1 & 0.28571429 & 0.34782609 & 0.18181818 \\
St2 & 0.28571429 & 1 & 0.3 & 0.10526316 \\
St3 & 0.34782609 & 0.3 & 1 & 0.095238095 \\
St4 & 0.18181818 & 0.10526316 & 0.095238095 & 1 \\
\hline
\end{tabular}

Invertebrate communities present the greatest similarity between stations 1 and 3 . In environmental terms, stations 1 and 3 are different but the algal cover is quite similar, $51 \%$ and $46 \%$ respectively. The algae cover greatly affects the similarity of the invertebrate communities on the Nglambor coast. Several factors, such as water $\mathrm{pH}$, water temperature, and salt content affect the existence of an invertebrate species, but in this study, the algae cover area had more effect on similarity. 


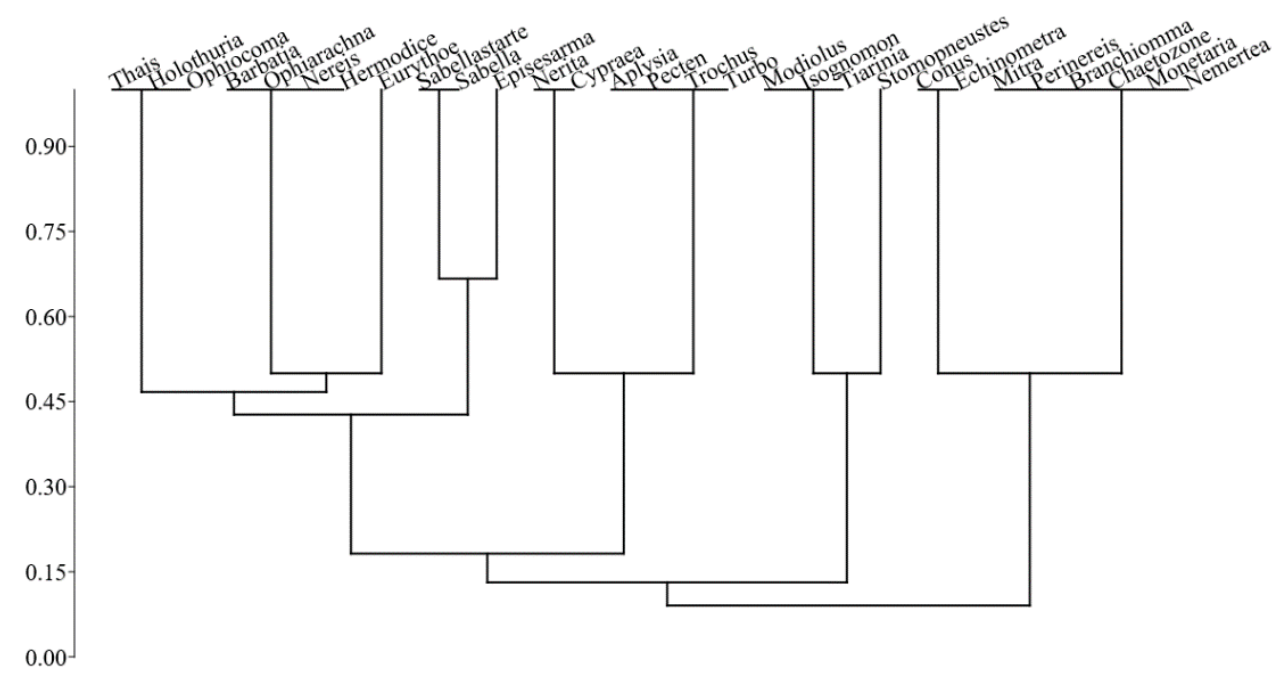

Fig 4. Dendrogram of invertebrate similarities in habitat use based on Jaccard's coefficient

Based on the invertebrate similarities in habitat use, it is known that there are four major branches. The cluster formed shows that there is a similar habitat use for each taxon. The cluster that is formed can consist of several phyla which show that the use of habitat between phyla influences each other.

The habitat use dendrogram indicates that a species can live in a certain environment with its abiotic needs. Several species originating from different phyla can have the ability to live in the same environment even though their niches will be different.

\section{Conclusion}

According to the research, each research station has different abiotic factors, such as water $\mathrm{pH}$, water temperature, salt content, and biotic factors, such as the area of algae cover. Differences in invertebrate communities exist at each research station due to differences in the amount of algal cover. Habitat use by each invertebrate at Nglambor Beach varies from group to group.

\section{References}

1. Supriyati, H., Ahzami, A., Sodiq, F., \& Khoiriyah, S. Biology, Medicine, \& Natural Product Chemistry, 8(1), 23-26 (2019)

2. Prasetya, T. A., Nazira, F. K., Millaty, I. N. K., Zulfikar, W. G., Nazara, F. A., \& Trijoko, T. Ocean Life, 1(2), 55-60 (2017).

3. Gibson, R. N. (2001). Encyclopedia of Ocean Sciences, 1348-1354 (2001).

4. Umanzor S, Ladah L, Calderon-Aguilera LE, Zertuche-González JA. Marine Ecology Progress Series, 584, 67-77 (2017).

5. Pereira, S. G., Lima, F. P., Queiroz, N. C., Ribeiro, P. A., \& Santos, A. M. Hydrobiologia, 555(1), 185-192 (2006).

6. Hurtt GC \& Pacala SW. Journal of Theoretical Biology 176, 1-12 (1995)

7. Hammer $\varnothing$, Harper DA, Ryan PD. Palaeontologia electronica 4 (1),9 (2001)

8. Dalirsefat, S. B., da Silva Meyer, A., \& Mirhoseini, S. Z. Journal of Insect Science. 9,1 (2009) 
9. Dash, Madhab Chandra and Satya Prakash Dash, Fundamentals of Ecology Third Edition, Tata McGraw Hill Education Private Limited (2009)

10. Souza, S., Matthews-Cascon, H., \& Couto, E. D. C. Série Zoologia, 110 (2020).

11. Khade, S. N., \& Khade, P. S. International Journal of Fauna and Biological Studies, 3(3), 01-04 (2016).

12. Jones, R. ICES Journal of Marine Science, 35(3), 225-243 (1974)

13. Suryanti, S., Ain, C., \& Latifah, N. Journal of Physics: Conference Series. 1025 (1), p 012038 (2018)

14. Wetzelhuetter, Christoph, ed. Groundwater in the coastal zones of Asia-Pacific. (Springer, Netherlands, 2013.)

15.Enríquez, S., Avila, E., \& Carballo, J. L. Journal of Phycology, 45(1), 81-90 (2009).

16. Gan, S. X., Tay, Y. C., \& Huang, D. Journal of the Marine Biological Association of the United Kingdom, 99(8), 1697-1707 (2019).

17. Norderhaug, K. M., Christie, H., \& Rinde, E. Marine Biology, 141(5), 965-973 (2002)

18. Veiga, P., Rubal, M., \& Sousa-Pinto, I. Marine environmental research, 101, 115-123 (2014 